\title{
The Importance of Self-Management in the Context of Personalized Care in COPD
}

\author{
Ana Cravo' \\ Darush Attar ${ }^{2}$ \\ Daryl Freeman ${ }^{3}$ \\ Steve Holmes ${ }^{4}$ \\ Lindsay Ip $^{5}$ \\ Sally J Singh (iD ${ }^{6,7}$
}

'Medical Affairs, Boehringer Ingelheim Ltd, Bracknell, UK; ${ }^{2}$ North Central London Clinical Commissioning Group (CCG), London, UK; ${ }^{3}$ Norfolk Community Health \& Care, Norwich, UK; ${ }^{4}$ The Park Medical Practice, Shepton Mallet, UK; ${ }^{5}$ King's Health Partners and Ealing Community Partners, London, UK; ${ }^{6}$ Faculty of Health and Life Sciences, Coventry University, Coventry, UK; ${ }^{7}$ Department of Respiratory Sciences, University of Leicester, Leicester, UK

Correspondence: Steve Holmes

The Park Medical Practice, Cannard's

Grave Road, Shepton Mallet, Somerset,

BA4 5RT, UK

Tel +441749334383

Email steve.holmes@btinternet.com

\begin{abstract}
Despite current guidelines and decades of evidence on the benefits of a selfmanagement approach, self-management of COPD remains relatively under-utilized in clinical care compared with other chronic diseases. However, self-management interventions can play a valuable role in supporting people with COPD to respond to changing symptoms, and thereby make appropriate decisions regarding the management of their own chronic condition. In this review, we discuss the history and evolution of the concept of selfmanagement, assess current multidisciplinary support programs and clinical interactions designed to optimize self-management, and reflect on how effective these are in terms of clinical and humanistic outcomes. We also evaluate the mechanisms for encouraging change from protocol-based care towards a more personalized care approach, and discuss the role of digital self-management interventions and the importance of addressing health inequalities in COPD treatment, which have been accelerated by the COVID-19 pandemic. Reflecting on the importance of self-management in the context of symptom monitoring and provision of educational support, including information from patient organizations and charities, we discuss the ideal components of a self-management plan for COPD and provide six key recommendations for its implementation: 1) better education for healthcare professionals on disease management and consultation skills; 2) new targets and priorities for patient-focused outcomes; 3) skills gap audits to identify barriers to self-management; 4) best practice sharing within primary care networks and ongoing professional development; 5) enhanced initial consultations to establish optimal self-management from the outset; and 6) negotiation and sharing of self-management plans at the point of diagnosis.
\end{abstract}

Keywords: chronic obstructive pulmonary disease, COPD, self-management, personalized care

\section{Introduction}

Non-communicable diseases (NCDs) cause approximately 40 million deaths each year, equivalent to around $70 \%$ of all deaths globally. ${ }^{1}$ Major contributors to the prevalence of NCDs are an increasing life expectancy and various lifestyle factors, such as tobacco use, physical inactivity, alcohol abuse and unhealthy diets. ${ }^{1}$ According to recent data released by the World Health Organization, longevity increased globally by $\geq 6$ years in 2019 compared with 2000 (average age: approximately 73 years vs 67 years, respectively). ${ }^{2}$ However, on average, only 5 of those additional years were lived in good health, which has led to the conclusion that people are living longer but with more disability. ${ }^{2}$ The increasing burden of NCDs such as cardiovascular disease, cancer, chronic lung diseases, mental health problems and diabetes has made their prevention and management a global priority. ${ }^{1,3}$ 
However, managing the needs of these long-term health conditions adds a substantial load to an already overstretched healthcare service that is struggling to cope with the demands of acute care, exacerbated by the COVID-19 pandemic. This is made more complex by the specialization of certain parts of healthcare when the majority of people in older age have multimorbidity. ${ }^{4}$

Chronic obstructive pulmonary disease (COPD) is a chronic respiratory condition characterized by

persistent respiratory symptoms and airflow limitation that is due to airway and/or alveolar abnormalities usually caused by significant exposure to noxious particles or gases. $^{5}$

It is currently the third-leading cause of death worldwide, disproportionately affecting individuals living in low- and middle-income countries, where over $80 \%$ of COPDrelated deaths occur. $^{6}$ In particular, individuals with lower socio-economic backgrounds are more likely to be affected. ${ }^{7}$ A core feature of COPD is that symptoms may change, often due to disease exacerbations and progression. Within this context, self-management is particularly important as people with COPD experience greater deterioration in their physical health and deal with more symptoms of depression compared with those with diabetes and cardiovascular disease. ${ }^{8}$ A report from the King's Fund showed that those with long-term conditions such as COPD are two to three times more likely than the general population to have a mental health disorder, with an average prevalence of $30-46 \%{ }^{9}$ Comorbid COPD and mental health conditions lead to higher rates of morbidity and mortality, as well as higher utilization of healthcare services. ${ }^{9,10}$ Thus, COPD self-management interventions play a valuable role in supporting people to respond to changing symptoms, and thereby make appropriate decisions regarding the management of their own chronic condition. $^{11}$

Despite current guidelines and decades of evidence on the benefits of a self-management approach, selfmanagement of COPD remains relatively under-utilized. ${ }^{12}$ In this review, we evaluate the history and evolution of selfmanagement, assess the current applicability and implementation of self-management multidisciplinary support programs, and reflect on how effective these are in terms of clinical and humanistic outcomes. We assess the mechanisms for encouraging change from protocol-based care towards a more personalized care approach, and discuss the ideal components of a self-management plan for
Table I Key Recommendations for Self-Management

\begin{tabular}{|l|l|}
\hline Recommendation I & $\begin{array}{l}\text { Better education of HCPs delivering care to } \\
\text { people with COPD (both from a disease- } \\
\text { specific perspective and a consultation-skills } \\
\text { perspective) to deliver better shared care } \\
\text { management }\end{array}$ \\
\hline Recommendation 2 & $\begin{array}{l}\text { A change in how healthcare is delivered to } \\
\text { encourage excellence by changing targets and } \\
\text { priorities to more patient-focused outcomes }\end{array}$ \\
\hline Recommendation 3 & $\begin{array}{l}\text { Focus on healthcare resources-using } \\
\text { primary care networks to allow best practice } \\
\text { sharing and make professional training and } \\
\text { education accessible to HCPs, and to patients } \\
\text { and their carers }\end{array}$ \\
\hline Recommendation 4 & $\begin{array}{l}\text { Development of skills gap audits to reflect } \\
\text { the barriers to providing better access to } \\
\text { patient-centered education and self- } \\
\text { management }\end{array}$ \\
\hline Recommendation 6 & $\begin{array}{l}\text { An enhanced first consultation given by } \\
\text { appropriately qualified clinicians to provide } \\
\text { correct diagnosis and management, patient } \\
\text { education and engagement } \\
\text { plan at the point of diagnosis }\end{array}$ \\
\hline
\end{tabular}

Abbreviations: COPD, chronic obstructive pulmonary disease; $\mathrm{HCP}$, healthcare professional.

COPD, providing key recommendations regarding its implementation (Table 1). We also consider the role of digital interventions and health inequalities in COPD treatment, accelerated by the COVID-19 global pandemic.

\section{History and Evolution of Self-Management}

The concept of self-management is not new and has been around for many years. Back in 1957, Michael Balint, a Hungarian psychoanalyst, developed many ideas and concepts around the doctor-patient relationship, all of which are still relevant to clinical practice today. His theories depend heavily on three aspects of clinical practice: (1) the personal qualities of the clinician; (2) the clinician's skills; and (3) the wider socio-economic and political context of clinical practice. ${ }^{13}$ Later, in 1979, Stott and Davis recorded medical consultations highlighting the importance of active listening as a new concept and emphasized that the full potential in each consultation depends on the clinician's ability to communicate with 
A

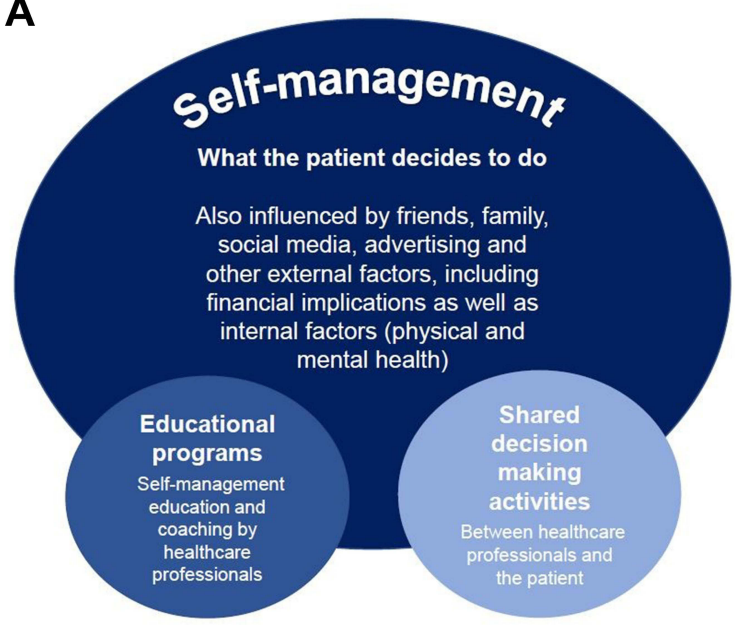

B

Educational programs may include:

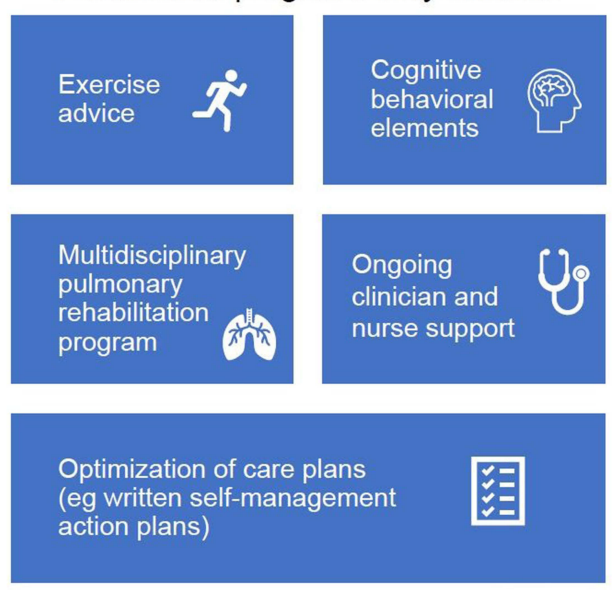

Figure I Self-management strategies. (A) Factors influencing effectiveness of self-management programs. (B) Components of educational programs.

his or her patients. ${ }^{14}$ A few years later, in 1988, Roger Neighbor published The Inner Consultation, which describes one of the most well-known consultation models, in which the importance of involving the patient in their own care was heavily discussed and referred to as shared management. ${ }^{15}$

Self-management programs, with the focus on the educational component, were defined in 2003 by Bourbeau et al as

any formalized patient education program aimed at teaching skills needed to carry out medical regimens specific to the disease, guide health behavior change and provide emotional support for patients to control their disease and live functional lives. ${ }^{16}$

Since then, definitions of self-management programs have evolved. While important factors include a formalized education program and shared decision-making activities between healthcare professionals (HCPs) and the patient, strategies for empowering patients to seek out their own information are also key (Figure 1A). The approaches that are currently considered as self-management interventions are very heterogeneous. They range from simply providing an information leaflet to more complex interventions that include multiple components, such as advice on exercise programs, cognitive behavioral elements such as cognitive behavioral therapy (CBT), ongoing clinician and nurse support and a multidisciplinary pulmonary rehabilitation (PR) program, as well as optimization of care plans (Figure 1B). ${ }^{11}$ Importantly, the effectiveness of a self-management intervention results not just from the program itself but also from the written action plans put in place to inform appropriate decisions regarding the management of the patient's condition. ${ }^{11}$
In a paper published by Effing et al in 2016, an international panel of COPD self-management experts reached consensus on the conceptual definition of a COPD selfmanagement intervention as

structured but personalized and often multi-component, with goals of motivating, engaging and supporting the patients to positively adapt their health behavior(s) and develop skills to better manage their disease. ${ }^{11}$

According to this definition, the key goals of the intervention include: (a) optimizing and preserving physical health; (b) reducing symptoms and functional impairments in daily life and improving emotional well-being, social well-being and quality of life; and (c) establishing effective alliances with HCPs, family, friends and community. ${ }^{11}$ This was an important step forward as it facilitated the identification of a more narrowly defined, but possibly less heterogeneous, evidence base. However, this definition does not fully incorporate patients' ideas and concerns, their expectations of the disease itself, the treatment and lifestyle options or their preferred choices. ${ }^{17,18}$

In 2017, the Global Initiative for Chronic Obstructive Lung Disease (GOLD) advocated that written selfmanagement action plans should become an integral part of evidence-based management of COPD. ${ }^{19}$ Two years later, GOLD reinforced that self-management education and coaching by HCPs should be a major component of the "Chronic care model" within the context of the healthcare system. ${ }^{20}$ National guidelines such as those of the National Institute for Health and Care Excellence (NICE) in the UK recommend that all patients with COPD should receive an individualized comprehensive management 
plan that includes educational material in order to improve their knowledge of the condition and its management. ${ }^{21}$ Furthermore, those at risk of exacerbations should be offered advice about how to recognize and respond promptly to the symptoms of an exacerbation. ${ }^{21}$ It is recommended that self-management plans include cognitive behavioral components as there is some evidence that these reduce distress. ${ }^{21}$ For COPD, self-management behaviors primarily involve early self-recognition and selfinitiation of treatment for exacerbation, compliance with medication and vaccination, quitting smoking, eating a healthy diet and taking regular physical exercise. ${ }^{22}$ Lung Foundation Australia also advocates the use of written action plans for COPD and provides a template to be completed by the clinician and patient together to guide the patient in recognizing when their symptoms change and what action they should take. ${ }^{23}$

The potential benefits of self-management in COPD have been reinforced by a Cochrane Review, which demonstrated positive outcomes in terms of respiratoryrelated hospital admissions and health-related quality of life (HRQoL), although there was "a small, but significantly higher respiratory-related mortality rate for selfmanagement compared to usual care." 24 Previous studies reported compliance rates of approximately $40 \%$ with selfmanagement advice among patients with COPD, particularly younger patients who were not living alone. ${ }^{25}$ However, the heterogeneous nature of self-management interventions complicates the development of a robust evaluation process that can assess the effectiveness of such interventions in the real world, and therefore it can be challenging to identify the optimal combination of components. Randomized clinical trials typically have small sample sizes, careful selection of patients (to minimize confounding) and a short-term follow-up, limiting the applicability and validity of findings, particularly from a long-term perspective. It is therefore important that the implementation and delivery of the interventions are subject to routine evaluation, as this would help ensure that they are delivering benefits to patients and allow the intervention content and format to be refined.

\section{Applicability and Implementation of Self-Management Programs}

Many people with COPD have high rates of emergency department visits and hospital admissions, often related to acute exacerbations, and these are costly to health services. ${ }^{26-28}$ Alongside the direct costs, there are other substantial indirect costs associated with the progression of the disease, which are much harder to quantify and relate to impact on family, lost days from work and social costs. ${ }^{29}$ As such, improving HRQoL and reducing hospital admissions represent important components of COPD management, both to healthcare systems and people with COPD. $^{30}$

Given the strong interest from health system administrators - including commissioners and developers - in strategies that rationalize costs, there is a strong need in both research and clinical settings to operationalize the conceptual definitions of COPD self-management interventions. Supporting patients to manage their own health may lead to improvements in clinical outcomes, which in turn reduce healthcare costs. ${ }^{31}$ Recent systematic reviews suggest that COPD self-management interventions may also improve HRQoL and reduce emergency department visits. ${ }^{30,32}$

In 2003, Bourbeau demonstrated a $40 \%$ reduction in hospitalizations for exacerbations of COPD in a multicenter, randomized controlled trial of selfmanagement with comprehensive patient education compared with usual care. ${ }^{16}$ In this study, patients were encouraged to follow an exercise program, involving stretching exercises, muscle exercises, and cardiovascular exercises (stationary bicycle, walking, or climbing stairs), at least three times per week for 30-45 minutes each time. ${ }^{16}$ Two years later, a Cochrane Review provided evidence that action plans help people with COPD to recognize severe exacerbations and react appropriately to them by self-initiating antibiotics and/or orally administered steroids. ${ }^{33}$ In 2009, Effing et al investigated the effectiveness of self-management in reducing the severity of exacerbations and found that self-treatment of exacerbations led to fewer exacerbation days and lower costs. ${ }^{34}$

More recently, a study conducted by Jolly et al suggested that exercise is an important component of selfmanagement. ${ }^{35}$ They concluded that improvements in HRQoL associated with self-management support are likely to be due to a reduction in dyspnea and related distress as a consequence of exercise and breathing techniques. ${ }^{35}$ However, while many self-management interventions increased HRQoL, little effect was seen on hospital admissions, ${ }^{35}$ which is important from a commissioning of service stance. The authors also note that their findings may not be generalizable due to an emphasis on patients with moderate-to-severe COPD. 
Improved mental health from increased physical activity, reduced fatigue, an altered perception about limitations in daily activities and an increased confidence in managing the condition were also important factors. ${ }^{35}$ A systematic review conducted across studies published between January 2013 and 1 April 2015 suggested that self-management, through education or potentially as a component of PR, confers significant health gains in people with COPD in terms of HRQoL. ${ }^{36}$ In another systematic review on self-management interventions for patients with COPD, multicomponent interventions involving structured exercise or enhanced professional care (such as proactive telephone calls from a respiratory HCP) were associated with better outcomes, including improvement in HRQoL and reduction in hospital admissions, compared with usual care. ${ }^{37}$ In a meta-analysis, the duration of the self-management intervention was found to be important, ie the longer the intervention (range: 1 day to 24 months), the greater the reduction in admissions. ${ }^{38}$ These findings concur with the observation from Pinnock et al that self-management is not a single event and continued HCP support is crucial to sustaining behavior change. ${ }^{39}$

Self-management is currently supported within PR programs, though access and uptake are still far from ideal. ${ }^{40}$ Despite its widely and well-established profile in reducing breathlessness and healthcare utilization (particularly beddays), ${ }^{41}$ the 2019 National Asthma and Chronic Obstructive Pulmonary Disease Audit Programme reported that $\mathrm{PR}$ is not offered to $13 \%$ of eligible patients with COPD in the UK, with a focus on those with more severe COPD. ${ }^{42}$ This is despite NICE recommending that all people with COPD with a recent hospitalization for an acute exacerbation should be referred for PR. ${ }^{21}$ In Canada, the situation is even worse, with less than $0.5 \%$ of those living with COPD and less than $1 \%$ of those living with moderate-to-severe COPD having access to evidencebased PR programs. ${ }^{43}$ Annual reviews in primary care, which are attended by the vast majority of patients with COPD and already cover smoking cessation, inhaler technique and referral to further services such as PR, should provide a good opportunity to discuss self-management. ${ }^{12}$ Undoubtedly, further research is needed regarding referral pathways for primary care, the availability of resources to support training and PR programs, and a better understanding of the reasons for poor engagement with existing services. ${ }^{12}$ One way to potentially improve engagement in $\mathrm{PR}$ is co-designing the program with patients in the local area, so that it is more fit for purpose and sensitive to the patients' circumstances, culture and needs. This is particularly important as COPD is more prevalent in people with more complex psychosocial needs, ${ }^{7}$ which may make engagement with traditional services more difficult.

\section{Barriers to Efficient Self-Management Care in COPD}

In contrast to the evolution of evidence in COPD, the roadmap of supported self-management in asthma ${ }^{44}$ has been much smoother and more straightforward. Enabling patients to recognize that their condition is deteriorating and take timely, appropriate action to prevent an exacerbation and possibly hospital admission is one of the key goals of self-management. However, qualitative studies in people with COPD highlight the difficulty patients have in recognizing the onset of an exacerbation, which delays the decision on whether to seek professional advice. ${ }^{45}$ Bucknell et al observed in their trial of self-management that only $42 \%$ of participants were "successful selfmanagers"; the difficulty in distinguishing the onset of an exacerbation may be one reason for the less optimistic findings in some patients. ${ }^{25}$ Notably, patients often describe the symptoms that indicate an exacerbation in a relatively vague way; thus, effective self-management in COPD must go beyond symptom recognition and treatment response to incorporate other components such as healthy lifestyle (diet and activity) and use of appropriate medications. ${ }^{39}$

According to Pinnock, self-management education should not be an optional extra and HCPs need to ensure that all patients have personalized advice to enable them to improve and optimize their treatment, which is aligned to value-based healthcare - an approach centered around maximizing outcomes that matter to patients and carers relative to the costs and resources required to produce these outcomes throughout the whole pathway of care. ${ }^{46}$ Education needs to go beyond providing information in a leaflet or teaching module and to work with the person to make it truly personalized. In order to do this, it is vital that HCPs are not only knowledgeable about COPD but also skilled in patient-centered consulting and spend time to understand and place in context patients' ideas, concerns and expectations, as well as their triaxial situation (physical/social/psychological). Better education of HCPs in how to deliver care to people with COPD - both from a disease-specific perspective and a consultation-skills 
perspective - will help to deliver better shared care management (Table 1, Recommendation 1). Fundamentally, self-management demands that the healthcare system is shaped in a way to ensure continuity of care, address the multimorbidities with which the patient is living and provide flexible access to professional advice. ${ }^{47}$ However, despite certain exceptions, ${ }^{4}$ there is a notable gap in the self-management literature regarding multimorbidity.

This poses challenges for self-management - especially in the context of COPD, as many individuals have more than one health condition-and emphasizes more than ever the importance of personalization rather than generic information suitable for a wider population. Comorbid conditions, such as coronary heart disease, pain, depression and anxiety, are commonly associated with COPD and have also been associated with higher levels of polypharmacy, higher mortality and an increase in the risk of hospitalization. $^{48}$ This presents a challenge for COPD patients as, for some, the management of their comorbidities may be a higher priority than their COPD. Importantly, there is no clear guidance on appropriate selfmanagement advice for patients with multimorbidity; however, primary care literature has advised on this since the 1980s. ${ }^{49}$ Demands from the different conditions may mask the symptoms of deterioration, and individualized and tailored professional advice may prove useful to help these patients to manage their condition appropriately, encouraging them to interpret and respond to deteriorating status promptly and effectively. ${ }^{39}$ Since generalists have oversight of the patients' entire medical and social history, the engagement of primary care HCPs is critical to increasing the uptake of enhanced self-management.

One of the key barriers to effective self-management is poor mental health, which includes emotional barriers to adjusting to living with a long-term condition like COPD. Patients may experience low mood when they see themselves as being "defeated" by COPD or experience anxiety when they perceive the condition to be unpredictable and uncontrollable, lacking the confidence to cope with it. This low mood and anxiety can in turn negatively affect self-management, such as a patient's ability to exercise effectively due to fear of breathlessness, to engage in pulmonary rehabilitation, or to reach out for social support. However, when patients with COPD and mental health needs that affect self-management are seen in an integrated service - one consisting of doctors, nurses and physiotherapists, as well as psychologists and psychiatrists, all collaborating to encourage selfmanagement-patients may experience significantly better physical functioning, mental health and quality of life, and spend less time in hospital. ${ }^{50,51}$

\section{Transitioning from Protocol-Based Care to Personalized Care in COPD}

There are two important components to self-management support: (1) a portfolio of techniques and tools that help patients choose healthy behaviors; and (2) a central transformation of the patient-HCP relationship into a collaborative partnership ${ }^{52}$ (Figure 1). Qualitative work has highlighted how people with severe COPD struggle with the fear of dependency on others. They often fear being seen as socially, physically and mentally vulnerable, and will often avoid HCP advice, seeking the help of family/friends instead to enable them to continue living independently. ${ }^{53}$ In this context, self-care is a key motivator for many people with long-term conditions and may encourage engagement in the clinical model of selfmanagement. ${ }^{39}$ Besides self-care, COPD disease awareness seems to be equally important in the sense that it allows patients to be proactive in their disease's management. A post hoc analysis by Baiardini et al suggested that COPD awareness among patients is related to better clinical outcomes and management of their condition. ${ }^{54}$ Education programs that raise the level of knowledge of patients and their carers are key players in the effective treatment and prevention of COPD. ${ }^{54}$ However, in a changing world of information and, indeed, educational interventions, our current evidence base may already be outdated for the new technology that the majority of our population use (and a minority may be even more disadvantaged without).

In order to support behavior change with the view of producing a sustainable effect, it is fundamental to increase patients' skills and confidence in managing their disease state. In addition, patients and HCPs must work together to develop tangible and realistic healthcare goals. Lorig and Holman identified a generic set of skills proven successful in increasing self-efficacy, and thus effective in self-management, including (a) problem-solving; (b) decision-making; (c) resource utilization; (d) forming a patient-healthcare provider partnership; and (e) taking action. $^{55}$ A change in how healthcare is delivered is needed to encourage excellence by changing targets and priorities to more patient-focused outcomes (Table 1, Recommendation 2). 
People living with COPD can encounter various HCPs from different disciplines across both primary and secondary care. Thus, the complex and diverse needs of patients with COPD and their social networks present a particular challenge for HCPs as people can find it frustrating to have to go through their story so many times. Self-management support programs should extend beyond symptom monitoring and encompass other multidisciplinary interventions such as PR, ${ }^{56}$ smoking cessation ${ }^{57}$ and health/psychosocial support. ${ }^{58}$ People with COPD may need help to continue to live independently as their disease progresses, including support from occupational therapists, physiotherapists and social care services. ${ }^{59}$ In addition to this, training on inhaler technique and medicines management, managing breathlessness, and promotion of an active and healthy lifestyle are also important factors in these programs. This needs to be constructed on an understanding of the preferences and needs of the patient's own lifestyle, values and beliefs. As discussed already, despite being embedded within the clinical guidelines for COPD, there are no explicit self-management delivery strategies specified for the different professional roles taking part in the multidisciplinary team (MDT). Implementation studies that have explored a whole-systems approach in COPD are sparse, ${ }^{60}$ but evidence from other chronic conditions such as asthma and diabetes has shown significant improvements in clinical and health outcomes. ${ }^{60,61}$ From the few qualitative studies in COPD available, one study that explored the views of HCPs integrated into an MDT model found that the HCP's main specialty, experience and interest in $\mathrm{COPD} /$ respiratory medicine was the dominant factor that influenced how COPD self-management was implemented in practice. The more specialist HCPs appeared to have a better, all-embracing understanding of self-management of their specialist condition, whereas the generalist HCPs from a primary care setting engaged differently in COPD self-management and were more focused on exacerbation management. ${ }^{62}$

Primary care has long been identified as a key provider of self-management education and support because of its reach and central role in chronic disease management. ${ }^{63}$ HCPs from the primary care setting are typically an individual's first point of contact with the health system and very often continue to be the contact for people with chronic diseases such as COPD for many years. Despite this, the education given to HCPs does not always include evidence-based guidance to support self-management in COPD or encourage behavior change in patients. ${ }^{31}$ In addition, although awareness of the importance of selfmanagement is increasing within the primary care community, time pressures and resource constraints within the current operating environment are potential barriers to the inclusion of thorough self-management support. ${ }^{12}$ To help address this, primary care networks should allow best practice sharing and make professional training and education accessible to HCPs, patients and their carers (Table 1, Recommendation 3). As well as lack of time, a study involving interviews with nurses and allied HCPs across healthcare boundaries have identified other challenges to self-management, including lack of insight regarding training needs and assumptions regarding patients' perceived self-management abilities. ${ }^{64}$ While the role of HCPs in delivering self-management support is well documented in the literature, there remains a gap in research regarding the specific training needs, how specific strategies might best be resourced and delivered, and what outcomes can be achieved. In order to facilitate collaboration between HCPs and patients, there should be increased emphasis on educating clinicians to deliver effective selfmanagement support programs and interventions. ${ }^{31}$ This can be optimized by developing skills gap audits to reflect the barriers to providing better access to patient-centered education and self-management (Table 1, Recommendation 4). Incentive schemes within primary care to allow for better education of HCPs and greater time allocation for the reviews and ongoing management of patients with COPD and other long-term care conditions would also help to address this. Furthermore, current incentive schemes within primary care networks need to be carefully implemented to ensure that device switching, eg for environmental reasons, is part of a fuller decisionmaking process in partnership with the patient - one that takes into account patient and healthcare resource requirements and resulting health impacts, as well as environmental impact. ${ }^{65}$

Pharmacists with suitable training can also play an important role in patient self-care by promoting better health, prevention and early detection of disease, managing patients with long-term conditions and taking greater clinical responsibility for patients. ${ }^{66}$ The introduction of a healthy living pharmacy framework can make a positive impact on community pharmacy services, enabling them to provide more services according to local need. ${ }^{66}$ Other services with significant pharmacy involvement that aim to improve the quality of patient care include the discharge medicines service, new medicines service and structured 
medication reviews. ${ }^{67,68}$ Pharmacists usually based in general practitioner (GP) practices can offer holistic structured medication reviews; however, consistent with the pressures facing GPs, time and resource constraints in the current operating environment may limit the extent of the support that pharmacists are able to provide.

Supported self-management is not a time-limited or single intervention delivered as a "one-size-fits-all" package; it should be an ongoing process relying on joint understanding, reviewing and shared decision-making, with the ultimate goal of empowering the person to make the right choices for them and live a better life with their condition. Tailoring and personalizing such programs to address each individual's needs is of paramount importance, particularly in terms of individual clinical, demographic and psychosocial characteristics. ${ }^{39}$ Importantly, no single intervention solution is suitable for all people, and combinations of strategies should be considered to support patients in the best possible way. At the outset of a patient's self-management journey, an enhanced first consultation given by appropriately qualified clinicians is crucial to provide correct diagnosis and management, and to maximize patient education and engagement (Table 1, Recommendation 5). Dineen-Griffin and coauthors reported that, after knowledge acquisition, enhancing a patient's decision-making skills or ability to problem-solve was most commonly associated with positive results. ${ }^{31}$ Actively encouraging symptom monitoring and having specific, clear healthcare goals were also identified as important factors. Likewise, strategies to improve patient responsibility regarding medication adherence and lifestyle choices were also associated with effective interventions. Negotiation and sharing of a self-management plan at the point of diagnosis is therefore a critical component to ensure that these objectives are met (Table 1, Recommendation 6). Strategies for stress management or psychological coping with a patient's condition are also commonly identified as effective, particularly those that integrated $\mathrm{CBT} .{ }^{31}$ Activities encompassed by the CBT program include identifying and challenging unhelpful thoughts, relaxation training for anger management, cognitive restructuring and assertiveness, and social skills training. ${ }^{69}$

\section{Reducing Health Inequality in the Treatment of COPD and the Increased Role of Digital Health}

Health inequalities, which are more evident in COPD than in many other major $\mathrm{NCDs},{ }^{70}$ can be defined as "significant differences in respiratory health that are closely linked to racial ancestry, social, economic and/or environmental differences". ${ }^{71}$ The association of COPD hospital admission rates with social deprivation, particularly in cases of undiagnosed COPD, highlights the need for improved services in deprived areas. ${ }^{72}$ Vulnerable populations from deprived areas experience instability in terms of the burden of disease, provision of/access to healthcare services, quality of care and health outcomes. Many disadvantaged groups face further barriers to healthcare, affecting access to prevention services, earlier detection and disease clinical management. Furthermore, other determinants such as differences in patterns of seeking care, health literacy, language and education also contribute to healthcare access. ${ }^{73}$ The COVID-19 pandemic has also deepened the already existing health inequalities in COPD care, which have been accentuated through requests to shield. Concerns about catching infection, low mood, anxiety through social isolation and increased deconditioning have caused predictable adverse health outcomes. ${ }^{74}$

Despite this, the COVID-19 pandemic has also had a positive impact, accelerating the uptake of innovation, especially in terms of digital and remote working. It is important that these solutions are maintained and developed further to improve primary healthcare services as we recover from the pandemic. ${ }^{75}$ With routine check-ups disrupted, primary care providers had to adapt quickly to maintain an adequate standard of care for chronically ill patients alongside providing acute care and dealing with potential COVID-19 cases. $^{75}$ There have been opportunities to embrace digital innovation, prompting a shift towards increased self-management, including online support groups and digital self-management tools to reduce feelings of isolation and to improve knowledge about the disease. However, concerns have been expressed around the inequality of access to technology. ${ }^{76}$

Notably, a recent study conducted throughout the pandemic reported improved adherence to daily controller medications for those with asthma and COPD. ${ }^{77}$ The impact on adherence is encouraging and hopefully will have a positive effect in improving control of COPD and minimizing the need for acute care. This shift in patient behavior provides an opportunity for a new post-pandemic era of healthcare services, where providers will be tasked with actively promoting self-management and online support. This ambition also aligns well with the goals outlined in the UK National Health Service long-term plan, including the creation of fully integrated, community-based 
healthcare, with support for urgent care at its core, as well as promoting patient self-care and self-management. ${ }^{78}$ Given the nature of the disease, implementation of a selfmanagement trial program in patients with COPD will require an evidence-based approach that acknowledges multimorbidity and considers how the different diseases interact. $^{36}$

In essence, COPD treatment needs to cross boundaries from inpatient care for acute events to outpatient and community-based care for long-term, ongoing selfmanagement of COPD. Thus, there has never been such a pressing need to challenge the current care models and move towards strategies that improve the efficiency and effectiveness of COPD care.

In this context, the use of technology to deliver medical/clinical interventions remotely is one of the promising care solutions. Remote consultations, using real-time video conferencing or telephone calls, email and smartphone messages, and remote monitoring are examples of technologies being used in an effort to bridge geographical barriers. ${ }^{79}$ Telephone consultations are not new and have been used widely in primary care in the UK, for example, since before 1990 to manage out-of-hours problems and in-hours issues for many patients, though there has been less use of video conferencing and email/smartphone solutions. Initial studies incorporating technology into selfmanagement interventions for patients with COPD have indicated that this strategy could result in fewer exacerbation-related hospital attendances; ${ }^{80}$ however, the authors in this paper conclude that evidence for effectiveness was inconsistent between studies, and the pooled effect size for physical function and quality of life was not significant.

Mobile device technology has substantially improved over the past decade and could play a role in facilitating awareness of and access to self-management strategies for patients living with long-term conditions. ${ }^{80}$ Research has been timely as the use of technology rapidly changes and the availability of video consultation has, for example, become much more accessible only in the last 36 months. Williams et al explored patient experience and acceptability of apps and suggested that such technology may be able to complement current clinical care. ${ }^{81}$ However, despite a significant number of studies in this field, metaanalyses investigating hospital admissions, physical activity, physical function, dyspnea and exacerbations have failed to demonstrate the effectiveness of these interventions for clinical outcomes when compared to usual care. ${ }^{80}$
This is a direct result of the heterogeneity of pooled data, including variations in study design, interventions, target populations, outcomes and small sample sizes. ${ }^{82,83}$ Future studies should aim to standardize the study methodology and outcomes used in this area of research in order to increase the comparability of future trials. In hospital care, digital technologies and computerized decision support systems have been implemented already, but practical use of the technologies for COPD remains limited. Nevertheless, digital health transformation has been recognized as a promising driving force to empower individual patients, reduce health inequalities and deliver innovative, high-quality healthcare.

\section{Conclusions}

As chronic respiratory diseases predictably become increasingly common, demand for programs that will enable and empower patients to assume more responsibility for their care management will only rise. Undesirable physical and emotional symptoms and impaired physical functioning can directly prevent patients from carrying out normal daily activities, including the ability to successfully self-manage. As a result, self-management of chronic conditions like COPD should be applied not only from the clinical perspective, but also the patient perspective, with a focus on humanistic outcomes that matter to the patient on an individual basis. Of note, the International Consortium for Health Outcomes Measurement has standard sets for many long-term conditions, aiming to give a comprehensive view of what matters most to patients. ${ }^{84}$ However, since COPD has not been included in these standard sets, designing a self-management program and support has been more challenging.

Despite NICE recommendations that all patients with COPD should receive an individualized self-management plan, implementation in practice is poor. ${ }^{12}$ A clear and robust root cause analysis is needed to understand this mismatch, and to work out feasible resourced solutions. In practical terms, self-management and shared decisionmaking need to be integrated within the routine of healthcare services. Robust healthcare systems have the potential to facilitate ongoing support; patient organizations and charities could contribute to the broader aspects of living with COPD and, in the future, technologic approaches to care delivery may improve efficiency. ${ }^{39}$ When considering the sustainability of self-management interventions within primary care, the total duration of the intervention, and the correlation of intervention duration with the number of 
strategies delivered, are important aspects. Alongside this, policy and funding alignment will also be a major determinant. As such, we must understand where the best compromise in these interventions lies for cost-effective and resource-limited approaches. Innovations with good potential to transcend the quality-cost trade-off such as coproduction, prevention and use of digital strategies should be considered. This is an important area for future research in order to understand and identify high-value interventions, potential barriers and enablers involved so that practitioners, policymakers and researchers get a robust evidence base of primary care providers' impact in the area.

Effing's proposed conceptual description of COPD self-management interventions was a significant step forward in this field. ${ }^{11}$ However, it did not have significant representation from primary care clinicians, who provide the majority of care in this group, nor their perspectives at a wider holistic level. It mostly considers factors operating at the patient and HCP level rather than the organizational level. Added to this, there is currently limited evidence of how organizational/system-level factors affect selfmanagement of COPD, in particular the perspectives from key stakeholders such as commissioners and policymakers. Despite these challenges, this remains a vital area of practice in order to enable patient empowerment and self-management so that our patients obtain the best outcomes possible.

Finally, while the self-management approach has been explored fairly extensively from the patient perspective, research is still scarce regarding HCP perspectives. The few existing studies in the field have either explored specific areas of self-management such as PR, COPD guidelines and care recommendations, or have focused on particular HCPs, rather than considering the wider MDT, the multimorbidity agenda and the need to provide support on the physical conditions as well as psychological and social help. Whilst the healthcare system is divided into specialist/generalist practice, there is a pressing need to provide a more consistent and joined-up self-management strategy that is implementable across boundaries and strengthens the system primarily to benefit the patient.

In summary, this review reflects on the importance of self-management support for patients with COPD within the context of symptom monitoring and provision of educational support, including information from patient organizations and charities. We have provided recommendations to improve shared-care management of
COPD by means of better education of HCPs, identification of skills gaps and sharing of healthcare resources to improve access to patient-centered self-management (Table 1). Self-management programs should have a greater focus on patient outcomes and incorporate an enhanced first consultation, involving negotiation and sharing of each patient's individual self-management plan from the time of diagnosis (Table 1). Overall, treatment of COPD should follow an approach that weighs benefit versus risk at the individual patient level. Identifying and using the right treatment, for the right patient, at the right time, should always underpin the treatment and management of patients living with COPD.

\section{Abbreviations}

CBT, cognitive behavioral therapy; COPD, chronic obstructive pulmonary disease; GOLD, Global Initiative for Chronic Obstructive Lung Disease; GP, general practitioner; HCP, healthcare professional; HRQoL, healthrelated quality of life; MDT, multidisciplinary team; NCD, non-communicable disease; NICE, National Institute for Health and Care Excellence; PR, pulmonary rehabilitation.

\section{Acknowledgments}

The authors would like to express thanks to David Jones and James Bevan from the Market Access team at Boehringer Ingelheim for their valuable input into the healthcare resource utilization and health inequalities topics discussed in this paper. Copy-editing assistance was provided by Cindy Macpherson of MediTech Media, a medical communications company contracted and funded by Boehringer Ingelheim.

\section{Disclosure}

$\mathrm{AC}$ is an employee of Boehringer Ingelheim. DA reports speaker fees from AstraZeneca, Boehringer Ingelheim, Chiesi, Cipla, GlaxoSmithKline, Glenmark, Janssen, Johnson \& Johnson, Napp, Novartis, Orion, Pfizer, Scope, Teva, Thornton \& Ross and Trudell. SH reports personal fees from Boehringer Ingelheim, Chiesi, GlaxoSmithKline, Napp, Trudell, AstraZeneca, Roche, NHS England, Primary Care Respiratory Society, Health Education England and the Royal College of General Practitioners outside the submitted work. All authors participated in an advisory board on selfmanagement opportunities for patients with COPD organized by Boehringer Ingelheim, for which they received 
a consultancy fee. The authors report no other conflicts of interest in this work.

\section{References}

1. World Health Organization. Noncommunicable diseases; 2021. Available from: https://www.who.int/news-room/fact-sheets/detail/ noncommunicable-diseases. Accessed May 12, 2021.

2. World Health Organization. WHO reveals leading causes of death and disability worldwide: $2000-2019 ; 2020$. Available from: https:/ www.who.int/news/item/09-12-2020-who-reveals-leading-causes-ofdeath-and-disability-worldwide-2000-2019. Accessed April 29, 2021.

3. Wang $\mathrm{H}$, Naghavi $\mathrm{M}$, Allen $\mathrm{C}$, et al. Global, regional, and national life expectancy, all-cause mortality, and cause-specific mortality for 249 causes of death, 1980-2015: a systematic analysis for the global burden of disease study 2015. Lancet. 2016;388(10053):1459-1544.

4. Guthrie B, Payne K, Alderson P, McMurdo ME, Mercer SW. Adapting clinical guidelines to take account of multimorbidity. BMJ. 2012;345:e6341. doi:10.1136/bmj.e6341

5. Global Initiative for Chronic Obstructive Lung Disease. Global strategy for the diagnosis, management, and prevention of chronic obstructive pulmonary disease (2021 report); 2020 [Updated November 25, 2020]. Available from: https://goldcopd.org/wpcontent/uploads/2020/11/GOLD-REPORT-2021-v1.1-25Nov20 WMV.pdf. Accessed February 2, 2021.

6. World Health Organization. Chronic obstructive pulmonary disease (COPD); 2021. Available from: http://www.who.int/mediacentre/fact sheets/fs315/en/. Accessed August 19, 2021.

7. Grigsby M, Siddharthan T, Chowdhury MA, et al. Socioeconomic status and COPD among low-and middle-income countries. Int J Chron Obstruct Pulmon Dis. 2016;11:2497-2507. doi:10.2147/ COPD.S111145

8. Cramm JM, Nieboer AP. Self-management abilities, physical health and depressive symptoms among patients with cardiovascular diseases, chronic obstructive pulmonary disease, and diabetes. Patient Educ Couns. 2012;87(3):411-415. doi:10.1016/j.pec.2011.12.006

9. Naylor C, Parsonage M, McDaid D, Knapp M, Fossey M, Galea A. Long-term conditions and mental health. The cost of co-morbidities. The King's Fund and Centre for Mental Health; 2012. Available from: https://www.kingsfund.org.uk/sites/default/files/field/field_pub lication_file/long-term-conditions-mental-health-cost-comorbiditiesnaylor-feb12.pdf. Accessed August 92021.

10. Pumar MI, Gray CR, Walsh JR, Yang IA, Rolls TA, Ward DL. Anxiety and depression-Important psychological comorbidities of COPD. J Thorac Dis. 2014;6(11):1615-1631. doi:10.3978/j. issn.2072-1439.2014.09.28

11. Effing TW, Vercoulen JH, Bourbeau J, et al. Definition of a COPD self-management intervention: International Expert Group consensus. Eur Respir J. 2016;48(1):46-54. doi:10.1183/13993003.00025-2016

12. Khan A, Dickens AP, Adab P, Jordan RE. Self-management behaviour and support among primary care COPD patients: cross-sectional analysis of data from the Birmingham Chronic Obstructive Pulmonary Disease Cohort. NPJ Prim Care Respir Med. 2017;27(1):46. doi:10.1038/s41533-017-0046-6

13. Balint M. The Doctor, His Patient and the Illness. London: Churchill Livingstone; 1957.

14. Stott N, Davis R. The exceptional potential in each primary care consultation. J R Coll Gen Pract. 1979;29(201):201-205.

15. Neighbour R. The Inner Consultation. 1st ed. Oxford: Radcliffe Medical Press; 1987.

16. Bourbeau J, Julien M, Maltais F, et al. Reduction of hospital utilization in patients with chronic obstructive pulmonary disease: a disease-specific self-management intervention. Arch Intern Med. 2003;163(5):585-591. doi:10.1001/archinte.163.5.585
17. Tate P. Ideas, concerns and expectations. Medicine. 2005;33 (2):26-27. doi:10.1383/medc.33.2.26.58376

18. McKinley RK, Middleton JF. What do patients want from doctors? Content analysis of written patient agendas for the consultation. $\mathrm{Br}$ J Gen Pract. 1999;49(447):796-800.

19. Vogelmeier CF, Criner GJ, Martinez FJ, et al. Global strategy for the diagnosis, management and prevention of chronic obstructive lung disease 2017 report: GOLD executive summary. Respirology. 2017;22(3):575-601. doi:10.1111/resp.13012

20. Global Initiative for Chronic Obstructive Lung Disease. Global strategy for the diagnosis, management, and prevention of chronic obstructive pulmonary disease (2020 report); 2019. Available from: https://goldcopd.org/wp-content/uploads/2019/11/GOLD-2020REPORT-ver1.0wms.pdf. Accessed June 15, 2020.

21. National Institute for Health and Care Excellence. Chronic obstructive pulmonary disease in over 16s: diagnosis and management; 2018. Available from: https://www.nice.org.uk/guidance/ng115/resources/ chronic-obstructive-pulmonary-disease-in-over-16s-diagnosis-andmanagement-pdf-66141600098245. Accessed April 29, 2021.

22. Kuzma AM, Meli Y, Meldrum C, et al. Multidisciplinary care of the patient with chronic obstructive pulmonary disease. Proc Am Thorac Soc. 2008;5(4):567-571. doi:10.1513/pats.200708-125ET

23. Yang IA, George J, McDonald CF, et al. The COPD-X plan: Australian and New Zealand guidelines for the management of chronic obstructive pulmonary disease. Version 2.63, February, 2021; 2021. Available from: https://copdx.org.au/copd-x-plan/. Accessed August 102021.

24. Lenferink A, Brusse-Keizer M, van der Valk PD, et al. Self-management interventions including action plans for exacerbations versus usual care in patients with chronic obstructive pulmonary disease. Cochrane Database Syst Rev. 2017;8(8):CD011682. doi:10.1002/ 14651858.CD011682.pub2

25. Bucknall CE, Miller G, Lloyd SM, et al. Glasgow supported self-management trial (GSuST) for patients with moderate to severe COPD: randomised controlled trial. BMJ. 2012;344:e1060. doi:10.1136/bmj.e1060

26. Department of Health. An outcomes strategy for chronic obstructive pulmonary disease (COPD) and asthma in England; 2011. Available from: https://assets.publishing.service.gov.uk/government/uploads/ system/uploads/attachment_data/file/216139/dh_128428.pdf. Accessed April 29, 2021.

27. Britton M. The burden of COPD in the U.K.: results from the confronting COPD survey. Respir Med. 2003;97 Suppl C(Suppl C): S71-79. doi:10.1016/S0954-6111(03)80027-6

28. Chapman KR, Mannino DM, Soriano JB, et al. Epidemiology and costs of chronic obstructive pulmonary disease. Eur Respir J. 2006;27(1):188-207. doi:10.1183/09031936.06.00024505

29. Patel JG, Nagar SP, Dalal AA. Indirect costs in chronic obstructive pulmonary disease: a review of the economic burden on employers and individuals in the United States. Int $J$ Chron Obstruct Pulmon Dis. 2014;9:289-300. doi:10.2147/COPD.S57157

30. Newham JJ, Presseau J, Heslop-Marshall K, et al. Features of self-management interventions for people with COPD associated with improved health-related quality of life and reduced emergency department visits: a systematic review and meta-analysis. Int J Chron Obstruct Pulmon Dis. 2017;12:1705-1720. doi:10.2147/COPD.S133317

31. Dineen-Griffin S, Garcia-Cardenas V, Williams K, Benrimoj SI. Helping patients help themselves: a systematic review of self-management support strategies in primary health care practice. PLoS One. 2019;14(8):e0220116. doi:10.1371/journal.pone.0220116

32. Yadav UN, Lloyd J, Hosseinzadeh H, Baral KP, Harris MF. Do chronic obstructive pulmonary diseases (COPD) self-management interventions consider health literacy and patient activation? a systematic review. J Clin Med. 2020;9(3):646. doi:10.3390/ jem9030646 
33. Turnock AC, Walters EH, Walters JA, Wood-Baker R, Action plans for chronic obstructive pulmonary disease. Cochrane Database Syst Rev. 2005;4:CD005074. doi:10.1002/14651858.CD005074.pub2

34. Effing T, Kerstjens H, van der Valk P, Zielhuis G. van der Palen J. (Cost)-effectiveness of self-treatment of exacerbations on the severity of exacerbations in patients with COPD: the COPE II study. Thorax. 2009;64(11):956-962. doi:10.1136/thx.2008.112243

35. Jolly K, Majothi S, Sitch AJ, et al. Self-management of health care behaviors for COPD: a systematic review and meta-analysis. Int J Chron Obstruct Pulmon Dis. 2016;11:305-326.

36. Murphy LA, Harrington P, Taylor SJ, et al. Clinical-effectiveness of self-management interventions in chronic obstructive pulmonary disease: an overview of reviews. Chron Respir Dis. 2017;14 (3):276-288. doi:10.1177/1479972316687208

37. Jordan RE, Majothi S, Heneghan NR, et al. Supported self-management for patients with moderate to severe chronic obstructive pulmonary disease (COPD): an evidence synthesis and economic analysis. Health Technol Assess. 2015;19(36):1-516. doi:10.3310/hta19360

38. Jonkman NH, Westland H, Trappenburg JC, et al. Characteristics of effective self-management interventions in patients with COPD: individual patient data meta-analysis. Eur Respir J. 2016;48(1):55-68. doi:10.1183/13993003.01860-2015

39. Pinnock H, Steed L, Jordan R. Supported self-management for COPD: making progress, but there are still challenges. Eur Respir J. 2016;48(1):6-9. doi:10.1183/13993003.00576-2016

40. Taylor SJ, Sohanpal R, Bremner SA, et al. Self-management support for moderate-to-severe chronic obstructive pulmonary disease: a pilot randomised controlled trial. Br J Gen Pract. 2012;62(603):e687-695. doi:10.3399/bjgp12X656829

41. Corhay JL, Dang DN, Van Cauwenberge H, Louis R. Pulmonary rehabilitation and COPD: providing patients a good environment for optimizing therapy. Int $J$ Chron Obstruct Pulmon Dis. 2014;9:27-39. doi:10.2147/COPD.S52012

42. Royal College of Physicians. National Asthma and Chronic Obstructive Pulmonary Disease Audit Programme (NACAP); 2019. Available from: https://www.rcplondon.ac.uk/projects/outputs/ national-asthma-and-copd-audit-programme-nacap-pulmonaryrehabilitation-clinical-0. Accessed May 18, 2021.

43. Camp PG, Hernandez P, Bourbeau J, et al. Pulmonary rehabilitation in Canada: a report from the Canadian Thoracic Society COPD clinical assembly. Can Respir J. 2015;22(3):147-152. doi:10.1155/ 2015/369851

44. Gibson PG, Powell H, Coughlan J, et al. Self-management education and regular practitioner review for adults with asthma. Cochrane Database Syst Rev. 2002;(1):CD001117. doi:10.1002/14651858. CD001117

45. Ure J, Pinnock H, Hanley J, et al. Piloting tele-monitoring in COPD: a mixed methods exploration of issues in design and implementation. Prim Care Respir J. 2012;21(1):57-64. doi:10.4104/pcrj.2011.00065

46. Pinnock H. Supported self-management for asthma. Breathe. 2015;11 (2):98-109. doi:10.1183/20734735.015614

47. Kielmann T, Huby G, Powell A, et al. From support to boundary: a qualitative study of the border between self-care and professional care. Patient Educ Couns. 2010;79(1):55-61. doi:10.1016/j. pec.2009.07.015

48. Chetty U, McLean G, Morrison D, Agur K, Guthrie B, Mercer SW. Chronic obstructive pulmonary disease and comorbidities: a large cross-sectional study in primary care. Br J Gen Pract. 2017;67 (658):e321-e328. doi:10.3399/bjgp17X690605

49. Pendleton D, Schofield T, Tate P, Havelock P. The Consultation: An Approach to Learning and Teaching. Oxford: Oxford University Press; 1984.

50. Ip L, Smith A, Papachristou I, Tolani E. 3 Dimensions for Long-Term Conditions - creating a sustainable bio-psycho-social approach to healthcare. Int J Integr Care. 2019;194:5. doi:10.5334/ijic.s3005
51. Gayle C, Ismail K. 3 Dimensions for Long-term Conditions (3DLC); 2021. Available from: https://www.kcl.ac.uk/research/3-dimensionsfor-long-term-conditions-3dlc. Accessed November 23, 2021.

52. Bodenheimer T, Wagner EH, Grumbach K. Improving primary care for patients with chronic illness. JAMA. 2002;288(14):1775-1779. doi:10.1001/jama.288.14.1775

53. Kendall M, Buckingham S, Ferguson S, et al. Exploring the concept of need in people with very severe chronic obstructive pulmonary disease: a qualitative study. BMJ Support Palliat Care. 2018;8 (4):468-474. doi:10.1136/bmjspcare-2015-000904

54. Baiardini I, Contoli M, Corsico AG, et al. Exploring the relationship between disease awareness and outcomes in patients with chronic obstructive pulmonary disease. Respiration. 2021;100(4):291-297. doi:10.1159/000513953

55. Lorig KR, Holman H. Self-management education: history, definition, outcomes, and mechanisms. Ann Behav Med. 2003;26(1):1-7. doi:10.1207/S15324796ABM2601_01

56. McCarthy B, Casey D, Devane D, Murphy K, Murphy E, Lacasse Y, Pulmonary rehabilitation for chronic obstructive pulmonary disease. Cochrane Database Syst Rev. 2015;2:CD003793. doi:10.1002/ 14651858.CD003793.pub3

57. Coronini-Cronberg S, Heffernan C, Robinson M. Effective smoking cessation interventions for COPD patients: a review of the evidence. JRSM Short Rep. 2011;2(10):78. doi:10.1258/shorts.2011.011089

58. Simpson E, Jones MC. An exploration of self-efficacy and self-management in COPD patients. Br J Nurs. 2013;22 (19):1105-1109. doi:10.12968/bjon.2013.22.19.1105

59. Higginson IJ, Bausewein C, Reilly CC, et al. An integrated palliative and respiratory care service for patients with advanced disease and refractory breathlessness: a randomised controlled trial. Lancet Respir Med. 2014;2(12):979-987. doi:10.1016/S2213-2600(14) 70226-7

60. Taylor SJC, Pinnock H, Epiphaniou E, et al. A rapid synthesis of the evidence on interventions supporting self-management for people with long-term conditions: PRISMS - Practical systematic review of self-management support for long-term conditions. Southampton (UK): NIHR Journals Library; Vol. 2, 2014.

61. Kauppi P, Linna M, Martikainen J, Makela MJ, Haahtela T. Followup of the Finnish Asthma Programme 2000-2010: reduction of hospital burden needs risk group rethinking. Thorax. 2013;68 (3):292-293. doi:10.1136/thoraxjnl-2011-201028

62. Ogunbayo OJ, Russell S, Newham JJ, et al. Understanding the factors affecting self-management of COPD from the perspectives of healthcare practitioners: a qualitative study. NPJ Prim Care Respir Med. 2017;27(1):54. doi:10.1038/s41533-017-0054-6

63. Kennedy A, Rogers A, Chew-Graham C, et al. Implementation of a self-management support approach (WISE) across a health system: a process evaluation explaining what did and did not work for organisations, clinicians and patients. Implement Sci. 2014;9(1):129. doi:10.1186/s13012-014-0129-5

64. Young HM, Apps LD, Harrison SL, Johnson-Warrington VL, Hudson N, Singh SJ. Important, misunderstood, and challenging: a qualitative study of nurses' and allied health professionals' perceptions of implementing self-management for patients with COPD. Int $J$ Chron Obstruct Pulmon Dis. 2015;10:1043-1052. doi:10.2147/COPD.S78670

65. Attar-Zadeh D, Lewis H, Orlovic M. Health-care resource requirements and potential financial consequences of an environmentally driven switch in respiratory inhaler use in England. $J$ Health Econ Outcomes Res. 2021;8(2):46-54. doi:10.36469/ jheor.2021.26113

66. Brown D, Portlock J, Rutter P, Nazar Z. From community pharmacy to healthy living pharmacy: positive early experiences from Portsmouth, England. Res Social Adm Pharm. 2014;10(1):72-87. doi:10.1016/j.sapharm.2013.04.014 
67. Hill A, Wilcock M. Exploring pharmacist involvement in the discharge medicines reconciliation process and information transfer to primary care: an observational study. Int J Clin Pharm. 2021. doi:10.1007/s11096-021-01300-8

68. NHS England. Case study: structured medication reviews and the primary care network multidisciplinary approach; 2020. Available from: https://www.england.nhs.uk/gp/case-studies/structuredmedication-reviews-and-the-primary-care-network-multidisciplinaryapproach/. Accessed July 6, 2021.

69. Heitkemper MM, Jarrett ME, Levy RL, et al. Self-management for women with irritable bowel syndrome. Clin Gastroenterol Hepatol. 2004;2(7):585-596. doi:10.1016/S1542-3565(04)00242-3

70. Pleasants RA, Riley IL, Mannino DM. Defining and targeting health disparities in chronic obstructive pulmonary disease. Int $J$ Chron Obstruct Pulmon Dis. 2016;11:2475-2496. doi:10.2147/COPD. S79077

71. Celedon JC, Roman J, Schraufnagel DE, Thomas A, Samet J. Respiratory health equality in the United States. The American Thoracic Society perspective. Ann Am Thorac Soc. 2014;11 (4):473-479. doi:10.1513/AnnalsATS.201402-059PS

72. Calderon-Larranaga A, Carney L, Soljak M, et al. Association of population and primary healthcare factors with hospital admission rates for chronic obstructive pulmonary disease in England: national cross-sectional study. Thorax. 2011;66(3):191-196. doi:10.1136/ thx.2010.147058

73. The Lancet Respiratory Medicine. COVID-19 casts light on respiratory health inequalities. Lancet Respir Med. 2020;8(8):743. doi:10.1016/S2213-2600(20)30308-8

74. Philip KEJ, Lonergan B, Cumella A, Farrington-Douglas J, Laffan M, Hopkinson NS. COVID-19 related concerns of people with long-term respiratory conditions: a qualitative study. $B M C$ Pulm Med. 2020;20(1):319. doi:10.1186/s12890-020-01363-9

75. The Lancet Respiratory Medicine. COVID-19 heralds a new era for chronic diseases in primary care. Lancet Respir Med. 2020;8(7):647. doi:10.1016/S2213-2600(20)30274-5
76. Tsutsui M, Gerayeli F, Sin DD. Pulmonary rehabilitation in a post-COVID-19 world: telerehabilitation as a new standard in patients with COPD. Int $J$ Chron Obstruct Pulmon Dis. 2021;16:379-391. doi:10.2147/COPD.S263031

77. Kaye L, Theye B, Smeenk I, Gondalia R, Barrett MA, Stempel DA. Changes in medication adherence among patients with asthma and COPD during the COVID-19 pandemic. J Allergy Clin Immunol Pract. 2020;8(7):2384-2385. doi:10.1016/j.jaip.2020.04.053

78. National Health Service. The NHS long term plan; 2019 [Updated August 21, 2019]. Available from: https://www.longtermplan.nhs.uk/ wp-content/uploads/2019/08/nhs-long-term-plan-version-1.2.pdf. Accessed April 30, 2021.

79. Ding H, Fatehi F, Maiorana A, Bashi N, Hu W, Edwards I. Digital health for COPD care: the current state of play. J Thorac Dis. 2019;11(Suppl 17):S2210-S2220. doi:10.21037/jtd.2019.10.17

80. Shaw G, Whelan ME, Armitage LC, Roberts N, Farmer AJ. Are COPD self-management mobile applications effective? A systematic review and meta-analysis. NPJ Prim Care Respir Med. 2020;30(1):11. doi:10.1038/s41533-020-0167-1

81. Williams V, Price J, Hardinge M, Tarassenko L, Farmer A. Using a mobile health application to support self-management in COPD: a qualitative study. $\mathrm{Br} J$ Gen Pract. 2014;64(624):e392-400. doi:10.3399/bjgp14X680473

82. Zwerink M, Brusse-Keizer M, van der Valk PD, et al. Self management for patients with chronic obstructive pulmonary disease. Cochrane Database Syst Rev. 2014;2014(3):CD002990.

83. Effing T, Monninkhof EM, van der Valk PD, et al. Self-management education for patients with chronic obstructive pulmonary disease. Cochrane Database Syst Rev. 2007;(4):CD002990. doi:10.1002/ 14651858.CD002990.pub2

84. International Consortium for Health Outcomes Measurement. Standard Sets. Start measuring outcomes that matter most to patients. Available from: https:/www.ichom.org/standard-sets/. Accessed July 6, 2021.

\section{Publish your work in this journal}

The International Journal of COPD is an international, peer-reviewed journal of therapeutics and pharmacology focusing on concise rapid reporting of clinical studies and reviews in COPD. Special focus is given to the pathophysiological processes underlying the disease, intervention programs, patient focused education, and self management protocols. This journal is indexed on PubMed Central, MedLine and CAS. The manuscript management system is completely online and includes a very quick and fair peer-review system, which is all easy to use. Visit http://www.dovepress.com/testimonials.php to read real quotes from published authors 